\title{
EVOLUCIÓN DEL ABANDONO DE TIERRAS DE CULTIVO EN LA COMARCA ORIENTAL DE LA REGIÓN DE MURCIA
}

\author{
J. E. Rodríguez Juan \\ Département de Géographie. Université Mohamed I. Oujda (Marruecos) \\ josedurj@gmail.com \\ A. Romero Díaz \\ Departamento de Geografía. Universidad de Murcia \\ arodi@um.es
}

\section{RESUMEN}

En la Comarca Oriental de la Región de Murcia, se analiza la superficie, distribución y evolución de tierras de cultivo abandonadas, mediante análisis espacial con herramientas SIG. Se observa un progresivo aumento del abandono en las últimas décadas, fomentado tanto por factores ambientales como económicos. Alrededor de un $15 \%$ de la superficie estudiada se encuentra en abandono y sometida a pérdidas de suelo, producidas por notables procesos de erosión. Por ello, el conocimiento del estado de estas áreas es fundamental para la toma de decisiones encaminadas a mitigar este grave problema.

Palabras clave: Abandono de cultivos, herramientas SIG, erosión de suelos, cubierta vegetal, Sureste de España.

\section{ABSTRACT}

The surface, distribution and evolution of land abandoned in the Eastern Region of Murcia, is analyzed using GIS spatial analysis tools. A progressive increase of abandonment has been observed in recent decades, favored by both environmental and economic factors. About the $15 \%$ of the studied surface is abandoned and, the majority of it, submitted to

Fecha de recepción: octubre 2013

Fecha de aceptación: noviembre 2014. 
significant soil loss. In semi-arid areas and marly lithologies, abandonment involves an increase in erosion processes. Therefore, the knowledge of the status of these areas is essential in order to take decisions to mitigate the problem.

Keyword: Land abandonment, semiarid areas, GIS tools, soil erosion, vegetal cover, Southeast of Spain.

\section{INTRODUCCIÓN}

A lo largo de la historia, los cambios de uso de la tierra se han convertido en una constante de los paisajes agrarios del Mediterráneo (García-Ruiz, 2010). El abandono de tierras no es un fenómeno reciente, pero en la actualidad constituye una verdadera preocupación para gran parte de los países mediterráneos, con una larga tradición agrícola. Además, una serie de cambios socio-económicos, ligados a condiciones climatológicas de semi-aridez, hacen que el fenómeno del abandono crezca y se llegue a convertir en una práctica agrícola habitual, que cuenta incluso con el respaldo de las instituciones responsables (Corbelle y Crecente, 2008).

\section{I.1. Causas del abandono de tierras de cultivo}

Según Pointereau et al. (2008) los factores que determinan el riesgo de abandono son de tipo geográfico, agro-ecológico, demográfico, socio-económico y de respuesta a políticas agrarias nacionales y europeas. Todas ellas pueden enmarcarse en dos categorías, por un lado, las provocadas desde una componente antrópica y, por otro, las estrictamente físicas.

Según García Ruiz y Lana Renault (2011), se pueden distinguir dos formas de abandono de campos de cultivo: (i) La primera es una forma de abandono espontánea, por decisión directa del propietario, y propiciada por cambios en las sociedades rurales. El interés por un mayor grado de rentabilidad de la tierra, unido a adversas condiciones ambientales como son la aridez y la degradación de los suelos provoca que el agricultor decida retirar del cultivo esas tierras. Este proceso condujo a la concentración de cultivos en el fondo de valles y en laderas suaves, abandonando las zonas agrícolas de media montaña. En el sureste peninsular este fenómeno se vio incrementado por sus condiciones semiáridas, además de los efectos edafológicos ocasionados por la masiva irrigación de suelos en la década de 1970, junto con la progresiva escasez de recursos hídricos. (ii) El otro tipo de abandono, que puede llamarse inducido, viene determinado por las políticas agrícolas a nivel nacional y, sobre todo, europeo. Esta forma de abandono ha sido controlado por la Política Agraria Común (PAC), cuyas funciones de regulación del mercado, con determinados productos agrícolas, ha fomentado la retirada de tierra cultivada (Baudry, 1991). En nuestra área de estudio el abandono se ha producido de manera predominante debido a la primera de las formas de abandono descritas, ya que según los datos de la Consejería de Agricultura de la CARM, han sido escasos los agricultores que, en esta comarca, se han acogido a la ayudas de la PAC.

En el primer grupo se incluyen, entre otras, las causas provocadas por los cambios producidos en la población de las zonas rurales, bien sea por el carácter migratorio de las últimas 
décadas, por el cambio estructural en la tenencia de la tierra que se ha experimentado en los países desarrollados, así como por la pérdida de competitividad frente a otros sectores de producción. Todo esto ha generado un rechazo de las nuevas generaciones a hacerse cargo de las actividades agrícolas, por lo que una buena parte del territorio se ha visto abocado al abandono (Baldock et al., 1996). Además, también habría que mencionar otros factores como los avances en las técnicas agrarias o las fluctuaciones de mercado, que promueven el abandono de las tierras marginales que no son capaces de obtener los máximos rendimientos. En sintonía con esto último, la PAC ha favorecido, a base de subsidios, que los agricultores dejen de producir algunos productos o reduzcan su porcentaje de producción, con el consiguiente abandono de parte de sus explotaciones (Lasanta et al., 2000; Ruiz Flaño, 1993).

Los condicionantes físicos también han jugado un papel muy importante en al abandono de tierras, en especial, en las regiones mediterráneas. Estas se caracterizan por su condición de «semiaridez», con precipitaciones escasas y muy irregulares que, en muchas ocasiones, llegan a ser torrenciales, junto a una acusada variabilidad climática (Cammeraat y Imeson, 1998). Por ello, muy buenas han de ser las características del sustrato edáfico para soportar las actividades agrícolas durante un largo período de tiempo. Pero, lamentablemente, ocurre todo lo contrario, pues las regiones mediterráneas poseen suelos poco profundos, con escasez de nutrientes, frágiles, en pendiente y sobre litologías que, en muchas ocasiones, no son aptas para el desarrollo agrícola (Cerdà, 1997). Con todo esto, se tiene como resultado un alto grado de vulnerabilidad de los suelos mediterráneos, áridos y semiáridos, que favorece el abandono de tierras de cultivo (López Bermúdez y Romero Díaz, 1998).

\section{II.2. Consecuencias del abandono de tierras de cultivo}

Las consecuencias del abandono es una cuestión que preocupa a la comunidad científica, bien sea por el desconocimiento de las repercusiones ambientales del abandono, en sus diferentes escenarios, como por el aumento porcentual de su extensión (Ruiz Flaño et al., 1991).

Para la región mediterránea, existen una gran cantidad de publicaciones científicas que intentan estudiar las complejidades del impacto directo e indirecto del abandono en el suelo. Un tema recurrente es el estudio de las terrazas de cultivo y su degradación. Estos estudios se han llevado a cabo principalmente en Castellón (Ruecker et al., 1998), Valencia (Cerdà, 1994), Alicante (Marco y Morales, 1995; Rodríguez et al., 1991; Asins Velis, 2009), Almería (Ferre et al., 1994) o Murcia (Romero Díaz et al., 2007).

En España, se han realizado diferentes estudios sobre las consecuencias ambientales, biológicas, hidrológicas y geomorfológicas que tienen lugar tras el abandono. Los territorios en los que se han desarrollado tales estudios han sido algunas cuencas y valles del Pirineo, el Sistema Ibérico riojano, algunos sectores del valle del Ebro y de la Región de Murcia. Los lugares en donde se ha realizado un mayor número de estudios en relación con las consecuencias del abandono de tierras de cultivo han sido, principalmente, el Pirineo y el sureste peninsular. (1) En el Pirineo, la mayoría han tratado el tema de los efectos geomorfológicos e hidrológicos (García-Ruíz y Lana-Renault, 2011) y son de citar los trabajos de García Ruiz et al., 1988, 1991, 1996; García Ruiz y Lasanta, 1994; Ruiz Flaño, 1993; Ruiz Flaño et al., 1991; Lasanta et al., 1994a, 1994b; Lasanta y Vicente Serrano, 2007; Lana-Renault et al., 2008; Arnáez et al., 2000; Gallart y Llorens, 1994; Llorens et al., 1992; Llorens y Gallart, 
1994; Molina y Nadal, 1998; Vicente-Serrano et al., 2006. (2) En el sureste español, los estudios se han centrado en las consecuencias del abandono en el sistema eco-geomorfológico, tales como las modificaciones en las relaciones suelo-agua-planta (Ruiz Sinoga y Martínez Murillo, 2008, 2009); los efectos de la variabilidad pluviométrica (Ruiz Sinoga y Romero Díaz, 2009); la incidencia en la respuesta hidrológica de las laderas (Ruiz Sinoga et al., 2003); o las repercusiones sobre los procesos de erosión del suelo (Ruiz Sinoga y Martínez Murillo, 2003; Cerdà, 1995; Cerdà et al., 1995a, 1995b). Otros trabajos a destacar por su temática son los relacionados con la dinámica sucesional de la vegetación tras el abandono (Álvarez, 1998; Francis, 1986; Pérez Latorre et al., 2008); la alternancia cultivo-abandono (Belmonte Serrato et al., 1999; Romero Díaz y Martínez Hernández, 2014) o las características de los suelos tras el abandono (Cerdà et al., 1994; García et al., 1997).

En ocasiones, el abandono de cultivos se ha considerado como una causa importante de la degradación de los suelos. No obstante, algunos investigadores abren la posibilidad de que estos espacios sean un lugar en el que la recuperación de los sistemas naturales sea una certeza (Padilla Blanco, 1998; Kosmas et al., 2008), siempre que tras el abandono se produzca la recuperación de la vegetación a corto y medio plazo. Son varios los estudios que demuestran que tras el abandono se puede producir un aumento sustancial de la cubierta vegetal y una recuperación de las características de los suelos, ya que mejora el contenido de materia orgánica, la capacidad de retención hídrica, la agregación y la estabilidad estructural del suelo, así como la conductividad hidráulica (Martínez-Fernández et al., 1996; Ruecker et al., 1998; Belmonte et al., 1999; Bonet, 2004; Romero Díaz et al., 2012; Robledano et al., 2012).

Por el contrario, en áreas semiáridas, como la analizada en este trabajo, con suelos ya degradados, la recuperación de la vegetación se produce de manera muy lenta o no se produce. Los suelos que han sido roturados y puestos en cultivo durante años pierden progresivamente materia orgánica y su estructura se degrada. Si además estos suelos son abandonados sin medidas de conservación y bajo unas condiciones climáticas semiáridas y con litologías erosionables, sufren una importante degradación física y biológica, actuando sobre ellos diferentes procesos de erosión y desertificación (Romero Díaz, 2003).

\section{I.3. Objetivos}

El objetivo principal de este trabajo ha sido evaluar las áreas de cultivo que han sido abandonadas en la Comarca Oriental de la Región de Murcia en las últimas décadas, tomando como referencia los años 1956, 1981, 2002 y 2011, así como analizar la evolución cronológica del abandono.

\section{II. ÁREA DE ESTUDIO}

La comarca analizada está integrada por los municipios de Abanilla y Fortuna, los cuáles constituyen la Comarca Oriental de la Región de Murcia (Figura 1). Ocupa una extensión de $385 \mathrm{~km}^{2}$ y tiene una altitud media de 385 metros. El 52\% del territorio se encuentra por debajo de los 400 metros, alrededor de un 30\% entre los 400 y los 600 metros y el $18 \%$ restante por encima de los 600 metros, teniendo como punto más alto el vértice de La Pila a 1.264 metros. El sector septentrional es el de mayor altitud y más montañoso, perteneciente, 
desde un punto de vista geológico, a las zonas externas de las Cordilleras Béticas. Por debajo de estos relieves se extiende una cuenca neógena-cuaternaria disectada por numerosas ramblas, con un drenaje vertiente al sur (Belmonte Serrato y Romero Díaz, 2007).

Responsable principal de las diferentes formas de modelado existentes en la comarca es la variedad de litologías que predominan: calizas y dolomías; formaciones detríticas; y margas, arcillas y yesos. Las calizas y dolomías se localizan en las sierras. Las formaciones detríticas se encuentran ampliamente, en forma de conos de derrubios y glacis, en los piedemontes de las sierras septentrionales de la comarca. Las margas, arcillas y yesos ocupan la depresión neógeno-cuaternaria, siendo de destacar el importante modelado de badland que se ha labrado en estos materiales blandos, con numerosos surcos, cárcavas, barrancos y ramblas, así como un notable desarrollo de procesos de piping (Romero Díaz et al., 2007).

\section{Figura 1}

LOCALIZACIÓN DEL ÁREA DE ESTUDIO

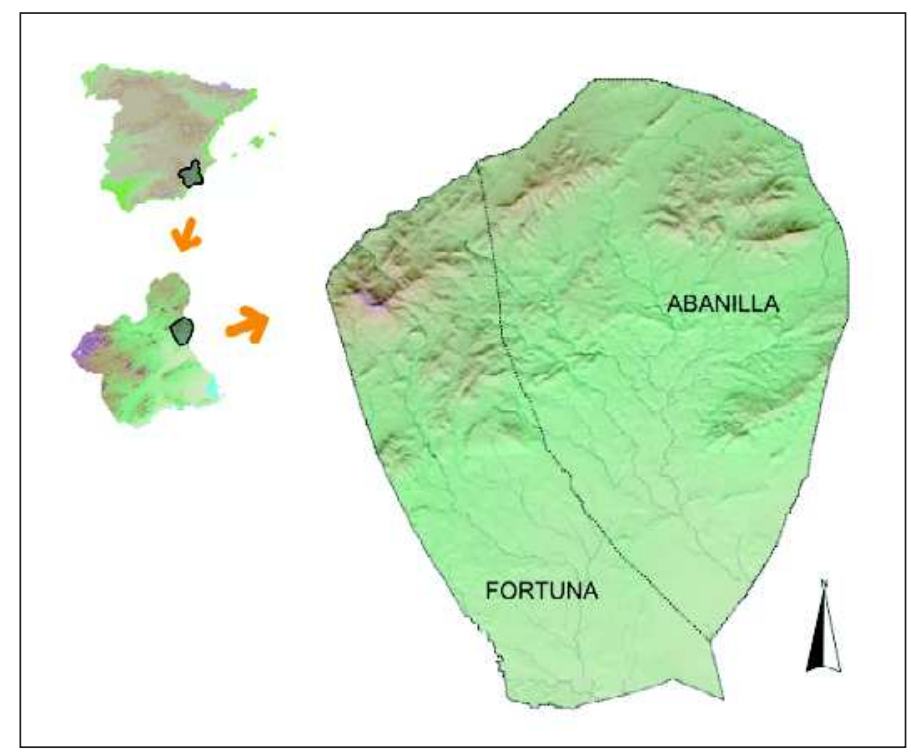

Fuente: elaboración propia.

Desde un punto de vista climático, la comarca está caracterizada por condiciones climáticas semiáridas, con precipitaciones escasas (inferiores a los $300 \mathrm{~mm}$ al año), irregulares y en ocasiones torrenciales ( $>150 \mathrm{~mm}$ en 24 horas). La temperatura media anual es de $19^{\circ} \mathrm{C}$ en Abanilla y $18,4^{\circ} \mathrm{C}$ en Fortuna, con veranos muy calurosos, con máximas de $44-45^{\circ} \mathrm{C}$ e inviernos templados. Resultado de estas condiciones semiáridas son los elevados índices de evapotranspiración potencial, de $952 \mathrm{~mm}$ en Abanilla y 954 mm en Fortuna (evaluada según Thornthwaite), lo que repercute en un acusado déficit hídrico, superior a los $650 \mathrm{~mm}$ (Belmonte Serrato y Romero Díaz, 2007).

En el área de estudio son tres los grupos de suelos predominantes (FAO, 2006): Regosoles $(36,3 \%)$, Calcisoles $(34,4 \%)$ y Leptosoles $(27,4 \%)$ (Figura 2). Los Regosoles predominan 
en las áreas de badlands y se desarrollan sobre margas de distinta edad y composición, y son muy pobres en materia orgánica, debido al continuo rejuvenecimiento que provocan los procesos de erosión y degradación a los que están sometidos. Los Calcisoles se extienden sobre los piedemontes y fondos de valle y se encuentran asociados a dos importantes unidades de segundo nivel: háplicos y pétricos. Los Calcisoles háplicos se localizan en las zonas de menor pendiente, siendo suelos aptos para la agricultura; mientras que los Calcisoles pétricos poseen un horizonte petrocálcico y alta pedregosidad. Los Leptosoles se localizan en las partes medias y altas de las sierras y se trata de suelos muy someros sobre roca continua y muy pedregosos (Ortiz Silla, 2007).

Figura 2

MAPA DE SUELOS DE LA COMARCA ORIENTAL DE LA REGIÓN DE MURCIA

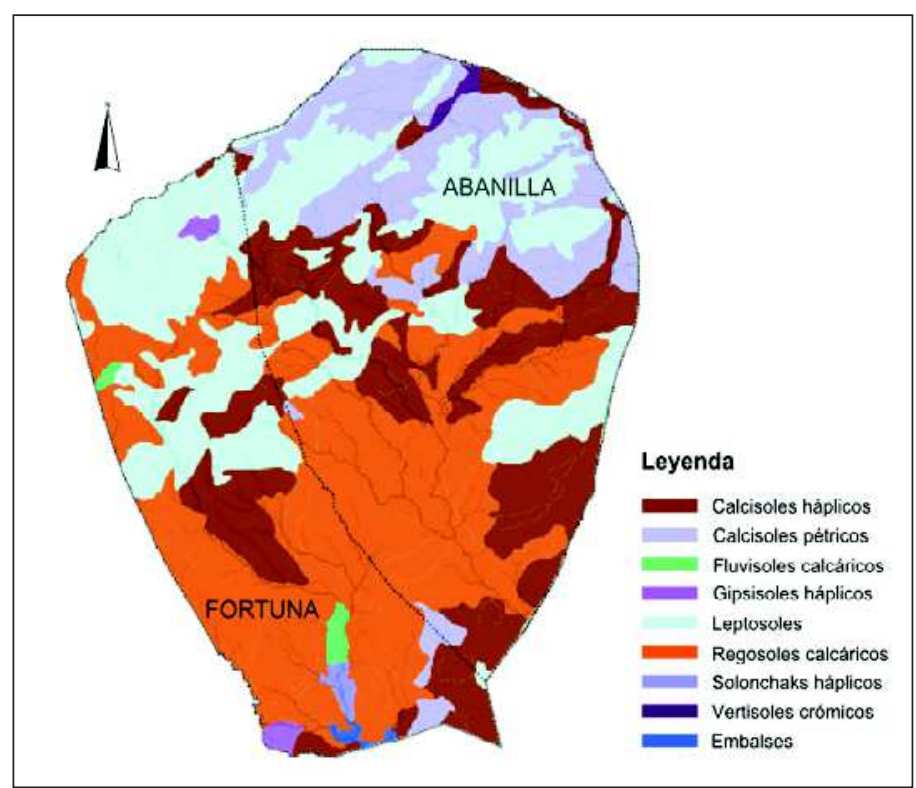

Fuente: Ortiz Silla (2007).

La vegetación potencial de la comarca está inmersa en una situación de extrema degradación, viéndose obligada a desarrollar métodos de adaptación a la aridez. En la mitad norte domina el ombrotipo seco de carrascal manchego mesomediterráneo, mientras que al sur dominan el ombrotipo semiárido y el piso termomediterráneo con matorrales y tomillares.

En resumen, tanto las condiciones edáficas, litológicas, climáticas y de cobertura vegetal de esta comarca reflejan unas características físicas no muy favorables para el desarrollo de la agricultura en gran parte de la comarca, por lo que estas pudieran ser, en gran medida, algunas de las causas del abandono de tierras.

Junto con los diferentes aspectos del medio físico que pudieran justificar el abandono, es necesario mencionar otros aspectos humanos también de relevancia como pueden ser la evolución demográfica o socioeconómica que ha tenido lugar en este territorio. 
La evolución de la población, tanto a nivel municipal como comarcal, muestra un ligero ascenso desde 1900 a 1970 (Figura 3), produciéndose, con posterioridad, un notable descenso consecuencia de un flujo de emigrantes importante, principalmente dedicados a la agricultura. Este hecho, sin duda, tiene su reflejo en el abandono que se ha podido constatar mediante fotointerpretación en el mismo periodo. En los inicios del siglo XXI se observa un incremento de la población, pero en este caso debido a los inmigrantes de países europeos, especialmente alemanes e ingleses, que debido a las benignas condiciones climáticas de la comarca han instalado aquí su residencia. En el año 2013 el 18\% de la población era extranjera y de esta el 72\% europea (CARM, 2013).

Figura 3

EVOLUCIÓN DE LA POBLACIÓN EN LA COMARCAABANILLA-FORTUNA

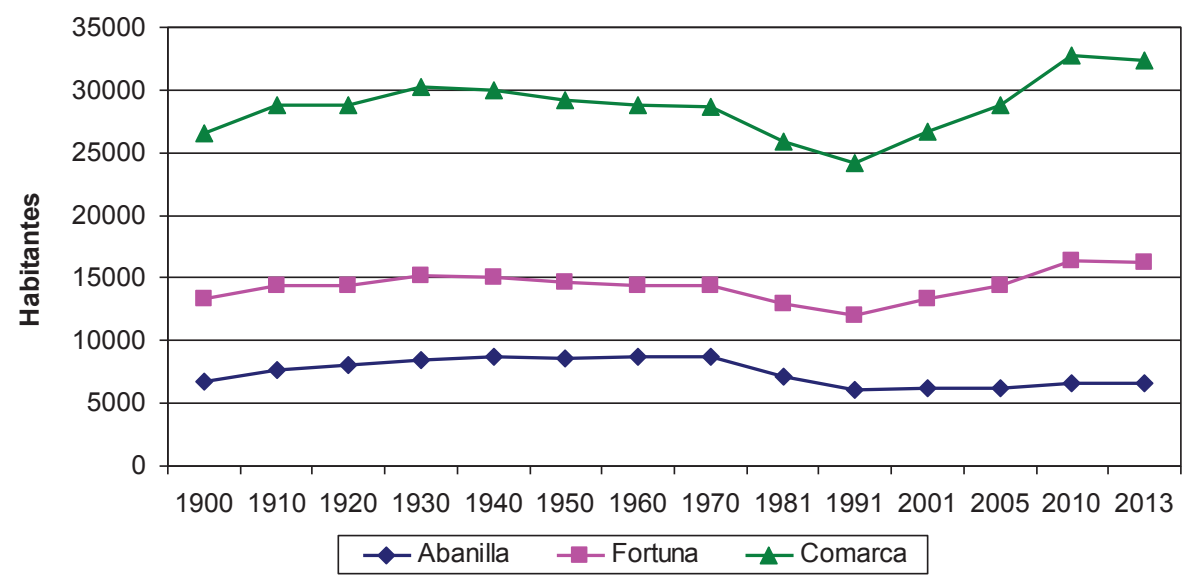

Fuente: elaboración propia a partir de datos de la CARM (2013).

Los cultivos ocupan aproximadamente el 55\% del territorio, predominando los cítricos. Respecto a la distribución de las tierras, es posible observar en la figura 4 cómo de 1989 a 2013 ha tenido lugar una disminución de las tierras dedicadas al cultivo y, por el contrario, un incremento de los pastizales, terrenos forestales y otras superficies, que podrían englobar gran parte de las superficies en abandono actuales.

En el caso del aprovechamiento de tierras en función de su dedicación (secano o regadío) los datos son bastante esclarecedores del fenómeno del abandono en la comarca. En los últimos 20 años, las tierras de cultivo en secano se han visto reducidas en un 30\% (5.079 ha). Gran parte de esa disminución del secano ha sido absorbida por el barbecho que se ha incrementado en 2.000 ha, seguido por el regadío (1.400 ha) (CARM 2012). Por tanto, se puede considerar que el abandono experimentado en la comarca, se ha llevado a cabo, casi exclusivamente, en explotaciones de secano y en cultivos leñosos, pues la comarca en su conjunto tiene una larga tradición en este tipo de aprovechamiento agrícola. La lista de cultivos que han dejado de desarrollarse en la comarca la encabezan los frutales no cítricos, en su mayoría almendros, los cuáles han pasado de las 3.734 ha en 2002 a 1.789 ha en 2011 . 
Otros grupos de cultivos que han disminuido su superficie son el viñedo con un abandono de 715 ha; el olivar con 167 ha menos; y las hortalizas que se han reducido en 37 ha. Por el contrario, los cítricos han experimentado un aumento de su producción, pasando de 1.705 ha en 2002 a 2.896 ha en 2011 (CARM 2012). En definitiva en el periodo 2002-2011, según datos estadísticos, se habrían dejado de cultivar 1.754 ha. Esta cifra se acerca mucho a la obtenida por fotointerpretación (realizada en este trabajo), la cual es de 1.319 ha en el mismo período de tiempo (Tabla 1).

Figura 4

DISTRIBUCIÓN GENERAL DE LA TIERRA EN LA COMARCAABANILLA-FORTUNA

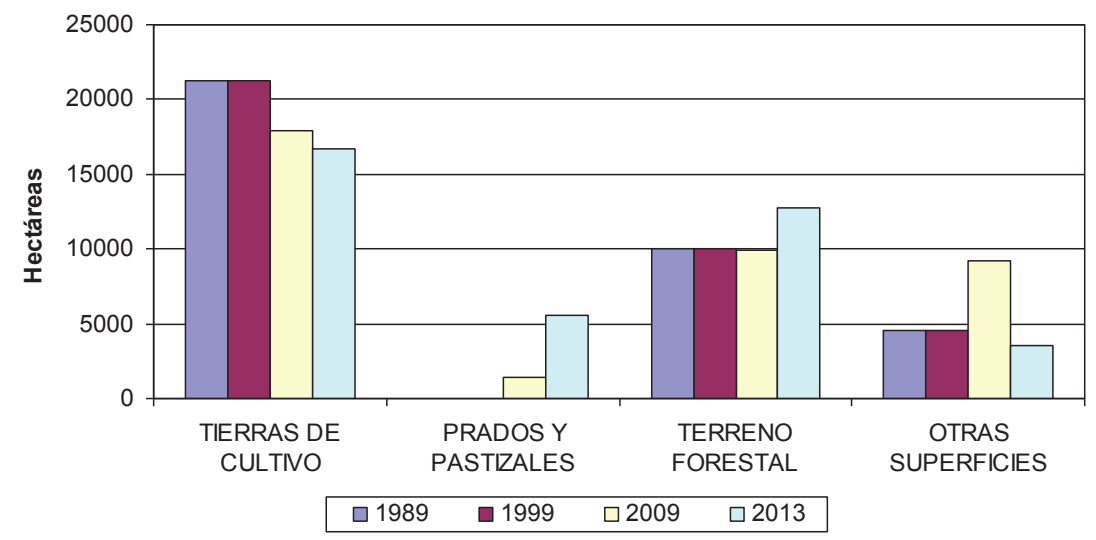

Fuente: elaboración propia a partir de datos de la CARM (2013).

\section{MÉTODOS}

\section{III.1. Recopilación cartográfica}

A través de los servicios WMS (Web Map Service) ofrecidos por Cartomur (Portal Digital del Servicio de Cartografía de la Dirección General de Ordenación del Territorio de la Región de Murcia), y el IMIDA (Instituto Murciano de Investigación y Desarrollo Agrario), se obtuvieron imágenes aéreas que sirvieron de base cartográfica. Se trata de las ortofotos digitales correspondientes a los años 1956, 1981, 2002 y 2011. Estas ortofotos son un conjunto de imágenes georeferenciadas que se utilizan como orientación gráfica. En el caso de la ortofoto de 1981, la ausencia de dos tiradas fotográficas nos ha obligado a corregir el error con una ortofoto de 1987, para al menos localizar el abandono más antiguo en ese momento. El resto de información cartográfica se obtuvo a través del Geocatálogo de los servicios de la Consejería de Agricultura y Agua, una herramienta concebida para facilitar el acceso a las diversas fuentes de información geográfica disponibles en línea y catalogadas por el SIGA (Sistema de Información Geográfica y Ambiental de la Región de Murcia). Del Instituto Geográfico Nacional también se obtuvieron otras capas de información. 


\section{III.2. Fotointerpretación y digitalización cartográfica del abandono}

Se ha llevado a cabo un análisis cartográfico mediante herramientas de software libre de tratamiento de la información geográfica (herramientas SIG). El software base utilizado ha sido gvSIG, programa informático para el manejo de información geográfica con precisión cartográfica que se distribuye bajo licencia GNU GPL v2. Permite acceder a información vectorial y rasterizada así como a servidores de mapas que cumplan las especificaciones del OGC (Open Geospatial Consortium).

Para determinar la distribución espacial de las tierras de cultivo abandonadas mediante digitalización se trabajó sobre cada una de las ortofotos en el sistema geodésico European Datum ED50, sobre proyección U.T.M. en el uso 30N (EPSG: 25830 - ETRS89), con una escala de trabajo de 1:3.000, y con la ayuda de una malla que hacía las veces de guía en la localización de las tierras abandonadas (Figura 5).

Figura 5 EJEMPLO DEL PROCESO DE DIGITALIZACIÓN DEL ABANDONO (ORTOFOTO DE 2011)

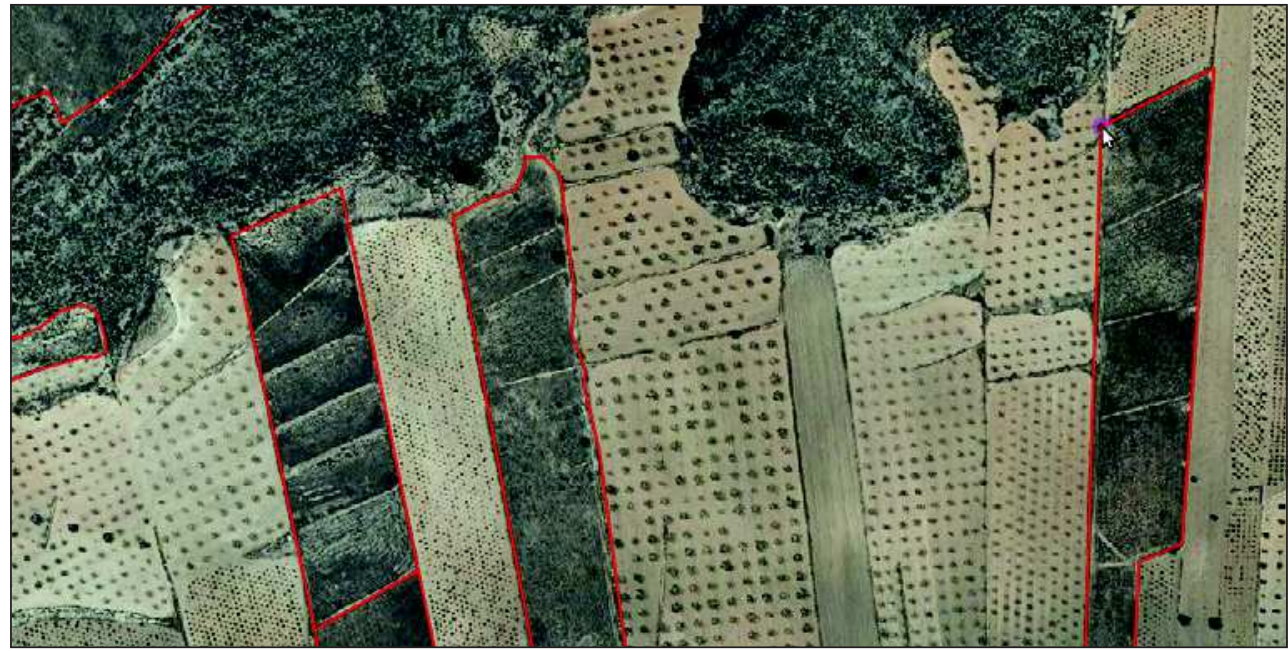

Fuente: elaboración propia.

En el caso de las ortofotos de 1956 y 1981 la dificultad a la hora de localizar el abandono fue mayor, pues estas imágenes están en blanco y negro. De especial dificultad fue el año 1956, por la cantidad de terreno cultivado y la baja calidad de la imagen. Para 1981 la tarea fue menos compleja, ya que el abandono se presenta en tonalidades oscuras y con un claro desorden y descuido del terreno, una vez que ha sido retirado del cultivo. Sin embargo, en las ortofotos de 2002 y 2011, la dificultad ya no fue localizar el abandono (que se visualizaba con facilidad en tramas con vegetación desordenada, una textura bastante más oscura que las zonas de cultivo y con señales de completa dejadez en el terreno), si no poder discernir entre barbecho reciente o abandono. Se decidió aceptar como abandono aquellos barbechos que, aparentemente, llevaran más de 2 años sin actividad agrícola. Para determinar esos años de 
barbecho se utilizó la visualización de la ortofoto de 2009, con el objeto de ser más exactos en la localización de las tierras de cultivo abandonadas. Es necesario mencionar, que es fácil cometer algún error, debido a la cantidad de distintos escenarios que se presentan en todo el espacio dedicado al cultivo, motivado, en parte, por los cambios en las políticas agrarias que provocan gran alternancia en los terrenos cultivados.

Cabe destacar también que los resultados obtenidos mediante la observación de las diferentes ortofotos, en la gran mayoría de los casos, se han verificado en campo.

\section{RESULTADOS Y DISCUSIÓN}

\section{IV.1. Cuantificación y evolución del abandono}

Mediante digitalización se elaboraron las distintas capas de abandono (shape) para los diferentes años. Estos shapes con datos de superficie y distribución del abandono nos acercan a la evolución y la realidad espacial del fenómeno en la comarca. Se puede observar de esta forma cómo y en qué lugares se han abandonado las tierras.

En la figura 6 (a, b, c y d) se constata el notable incremento del abandono desde el año 1956 al 2011. Los polígonos contabilizados en las imágenes de 1956 fueron 221; 3.037 en 1981; 8.199 en 2002; y 10.045 en 2011. Traduciendo los polígonos a superficies, el área total de abandono estimada para el conjunto comarcal en 2011 era de 5.646 ha (incluyendo aquellos barbechos que tenían más de dos años sin ningún tipo de aprovechamiento) (Tabla 1). La cifra es muy considerable, ya que representa el $14,6 \%$ de la superficie total de la comarca, y el $34 \%$ de las tierras de cultivo (a fecha de 2013). En la tabla 1 se aprecia el aumento constante que ha experimentado el abandono de tierras de cultivo en los últimos 50 años, pasando de representar un 0,6\% en 1956, al 14,6\% en el año 2011. Datos que, pese a no representar etapas equidistantes en años, reflejan que en los últimos nueve años el abandono de tierras ha experimentado su mayor aumento, pues en esos años el incremento es de 1.319 ha, mientras que para el resto de períodos las cifras aumentan pero no al mismo ritmo. Entre 1956 y 1981 (25 años) se produjo un incremento de tierras abandonadas de 1.934 ha, y entre 1981 y 2002 (21 años) el aumento fue de 2.150 ha.

Tabla 1 DISTRIBUCIÓN ESPACIAL DEL ABANDONO DE CULTIVOS A NIVEL COMARCAL Y MUNICIPAL

\begin{tabular}{|c|c|c|c|c|c|c|c|c|c|}
\hline \multirow{2}{*}{ Año } & \multicolumn{3}{|c|}{ Abanilla (23.562 ha) } & \multicolumn{2}{c|}{ Fortuna (14.933 ha) } & \multicolumn{2}{c|}{ Comarca (38.495 ha) } \\
\cline { 2 - 10 } & $\begin{array}{c}\text { Abandono } \\
\text { (ha) }\end{array}$ & Dif. & $\begin{array}{c}\text { Abandono } \\
(\%)(1)\end{array}$ & $\begin{array}{c}\text { Abandono } \\
(\text { ha })\end{array}$ & Dif. & $\begin{array}{c}\text { Abandono } \\
(\%)(1)\end{array}$ & $\begin{array}{c}\text { Abandono } \\
(\text { ha })\end{array}$ & Dif. & $\begin{array}{c}\text { Abandono } \\
(\%)(1)\end{array}$ \\
\hline $\mathbf{1 9 5 6}$ & 108 & -- & 0,45 & 135 & -- & 0,9 & 243 & -- & 0,63 \\
\hline $\mathbf{1 9 8 1}$ & 1.358 & +1.250 & 5,76 & 819 & +648 & 5,48 & 2.177 & +1.934 & 5,65 \\
\hline $\mathbf{2 0 0 2}$ & 2.706 & +1.348 & 11,48 & 1.621 & +802 & 10,86 & 4.327 & +2.150 & 11,24 \\
\hline $\mathbf{2 0 1 1}$ & 3.544 & +838 & 15,04 & 2.102 & +481 & 14,08 & 5.646 & +1.319 & 14,66 \\
\hline
\end{tabular}

(1) Con respecto a la superficie total del municipio o comarca.

Fuente: elaboración propia. 
Figura 6a

DISTRIBUCIÓN DE LA SUPERFICIE DE ABANDONO EN LA COMARCA DE ABANILLA-FORTUNA (AÑO 1956)

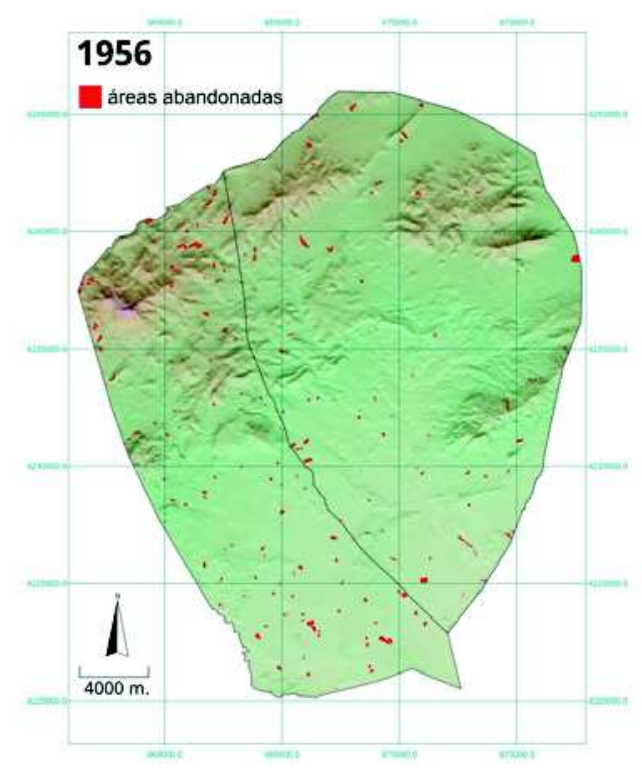

Figura $6 \mathrm{~b}$

DISTRIBUCIÓN DE LA SUPERFICIE DE ABANDONO EN LA COMARCA DE ABANILLA-FORTUNA (AÑO 1981)

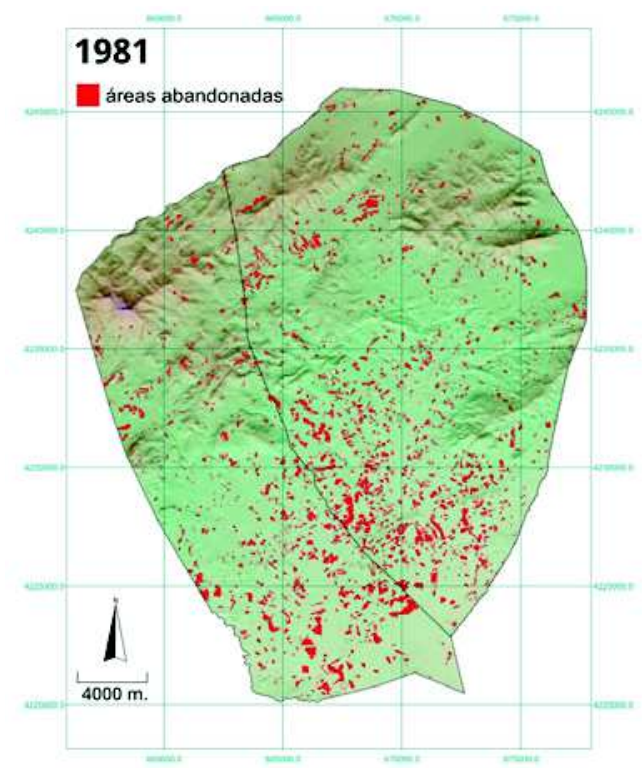


Figura 6c

DISTRIBUCIÓN DE LA SUPERFICIE DE ABANDONO EN LA COMARCA DE ABANILLA-FORTUNA (AÑO 2002)

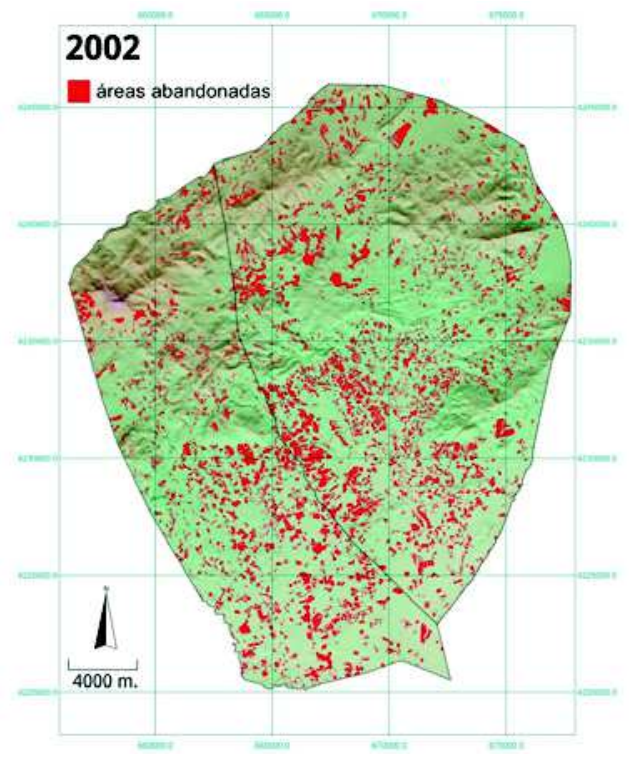

Figura 6d

DISTRIBUCIÓN DE LA SUPERFICIE DEABANDONO EN LA COMARCA DE ABANILLA-FORTUNA (AÑO 2011)

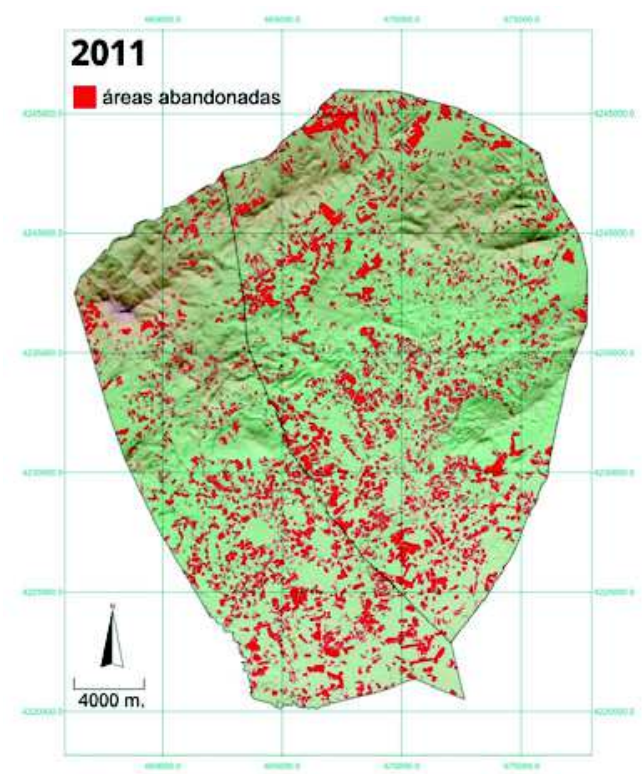




\section{IV.2. Distribución espacial del abandono}

Superponiendo la capa de abandono con el relieve de la comarca (Figura 6), se aprecia cómo el abandono se ha extendido, en el periodo 1956-1981, por zonas de media montaña o muy cercanas a los relieves montañosos, además de los abandonos en zonas agrícolas de menor pendiente. En época reciente, y gracias a la llegada del trasvase Tajo-Segura, es cuando mayor rendimiento agrícola se obtiene de las zonas más llanas, dejando en el olvido las tierras de cultivo que años atrás se establecieron en mayores pendientes, buscando la máxima extensión posible, pues la agricultura de entonces no se caracterizaba por la intensificación. Por el contrario, en el período 1981-2011, la distribución espacial del abandono se ha extendido, en mayor medida, por las zonas de menor pendiente y con mayores exigencias en el uso del suelo, posiblemente debido a los cambios en las políticas agrarias, controladas por los mercados.

Por municipios, Abanilla (con 23.562 ha de superficie total) en 2011 registraba 3.544 ha de tierras abandonadas, mientras que Fortuna (con 14.933 ha de superficie total) eran 2.102 ha las tierras en abandono. Si se analiza la cifra de hectáreas abandonadas en porcentajes, existe una pequeña diferencia entre Abanilla y Fortuna, siendo el primer municipio el que tiene un porcentaje algo mayor con un 15\%, frente al 14\% de Fortuna.

Se observa cómo hasta las décadas de los setenta y ochenta del siglo pasado, la retirada de tierras de cultivo no era un fenómeno tan acusado como en los últimos treinta años. En esta primera etapa el abandono se realizaba por razones relacionadas con el rendimiento de la tierra, los cambios en el consumo y la entrada de nuevas técnicas, que hacían de la agricultura una práctica mucho más intensiva. A partir de 1981 y con la posterior entrada de España en la Unión Europea, el aumento de las tierras de cultivo abandonadas es más acusado, posiblemente, y además de las causas mencionadas, por las medidas tomadas desde la PAC que, entre otras, recortan los niveles de producción en función de la demanda de los mercados, amplían el espectro de la competencia, así como el fracaso del modelo agrícola actual, en clara desventaja frente a otros sectores de producción españoles.

\section{IV.3. Edad del abandono}

Para poder determinar los efectos que provoca el abandono en las características geomorfológicas, hidrológicas y orgánicas del suelo, es importante conocer la edad del mismo, es decir el tiempo que los campos han permanecido sin ningún tipo de cultivo y labores agrícolas. Este dato siempre se ha conseguido datar con un previo trabajo de localización de parcelas de estudio y el posterior visionado de fotografías aéreas del lugar. Pero desde hace años esta tarea se ha simplificado gracias a las herramientas SIG y las ortofotos digitales.

En el caso de las áreas de abandono en la Comarca Oriental de la Región de Murcia, se han superpuesto las capas correspondientes a los distintos años en los que se ha trabajado, para determinar qué zonas coinciden y en qué período de tiempo. No obstante, hay que matizar que para datar el abandono, existe cierto margen de error si se trabaja con ortofotos con pocos años de diferencia. La mayor precisión se alcanza con imágenes más lejanas en el tiempo. 
Asumiendo posibles errores, se ha estimado que, en 2011, un 56,8\% del total de superficie de abandono lleva entre 10 y 30 años en esa situación (Tabla 2). Por otro lado, las zonas en abandono tanto en 1981, como en 2002 y 2011, por tanto con más de 30 años sin actividad agrícola, representan el 18,7\%. Este dato engloba la mayor parte del abandono que se produjo en la década de los 60 y 70, a raíz del cambio a una agricultura mucho más intensificada y que dejaba gran cantidad de espacios que habían sido aprovechados de forma extensiva sin mucho rendimiento agrícola. Ese 18,7\% de abandono de más de 30 años, pese a lo importante de la cifra, está compuesto por territorios de media montaña que no sufrieron grandes exigencias en la práctica agrícola y que, por tanto, en su mayoría han respondido bien a lo largo del tiempo al desarrollo de procesos de colonización vegetal. Por otro lado, las superficies de abandono más reciente han tenido lugar en zonas bajas, especialmente en la depresión margosa, en donde la recuperación de la cubierta vegetal tiene lugar de manera muy lenta (o no se realiza) y los procesos de erosión inciden de manera muy importante en estos suelos, incrementando las superficies de cárcavas y barrancos preexistentes, especialmente por procesos de erosión subsuperficial o piping (Figura 7).

Tabla 2

EDAD DEL ABANDONO

\begin{tabular}{|c|c|c|}
\hline Edad del abandono & Superficie (ha) & Porcentaje (\%) \\
\hline $\mathbf{< 1 0}$ años & 1.231 & 21,8 \\
\hline $\mathbf{1 0 - 3 0}$ años & 3.207 & 56,8 \\
\hline $\mathbf{3 0 - 5 0}$ años & 1.059 & 18,7 \\
\hline $\mathbf{> 5 0}$ años & 149 & 2,6 \\
\hline Total & 5.646 & 100 \\
\hline
\end{tabular}

Fuente: elaboración propia.

Además, es importante poner de manifiesto cómo los efectos del abandono son diferentes según la litología y el tipo de suelo, como así ha sido estudiado en otras áreas de la Región de Murcia (Romero Díaz, 2003; Romero Díaz, et al., 2012; Robledano et al., 2014). Así, sobre litologías predominantemente calizas y sobre Calcisoles y Leptosoles, que además coinciden en nuestra área de estudio con zonas de media montaña, su condición de marginalidad impuesta por lo abrupto del terreno y la falta de accesibilidad, asociado a un acusado descenso de presión sobre los recursos, ha permitido (en muchos casos) la regeneración de la cobertura vegetal natural, aunque de manera muy lenta. Aquí, el abandono, ha propiciado la mejora de las características edáficas de los suelos frente a los procesos de erosión, al incrementar su contenido en materia orgánica, nutrientes y mejorar su estructura. Por el contrario, en los Regosoles calcáricos desarrollados sobre litologías margosas, se han observado importantes procesos de erosión (Figura 7), producidos casi inmediatamente después del abandono de las tierras de cultivo. En estos casos, al ser suelos muy pobres y degradados, la recuperación de la cubierta vegetal es muy escasa o inexistente, aunque hayan pasado muchos años con posterioridad al abandono. 
Figura 7

EJEMPLOS DE PROCESOS DE EROSIÓN EN DIFERENTES CAMPOS DE CULTIVO ABANDONADOS SOBRE MARGAS EN LA CUENCA DE FORTUNA-ABANILLA

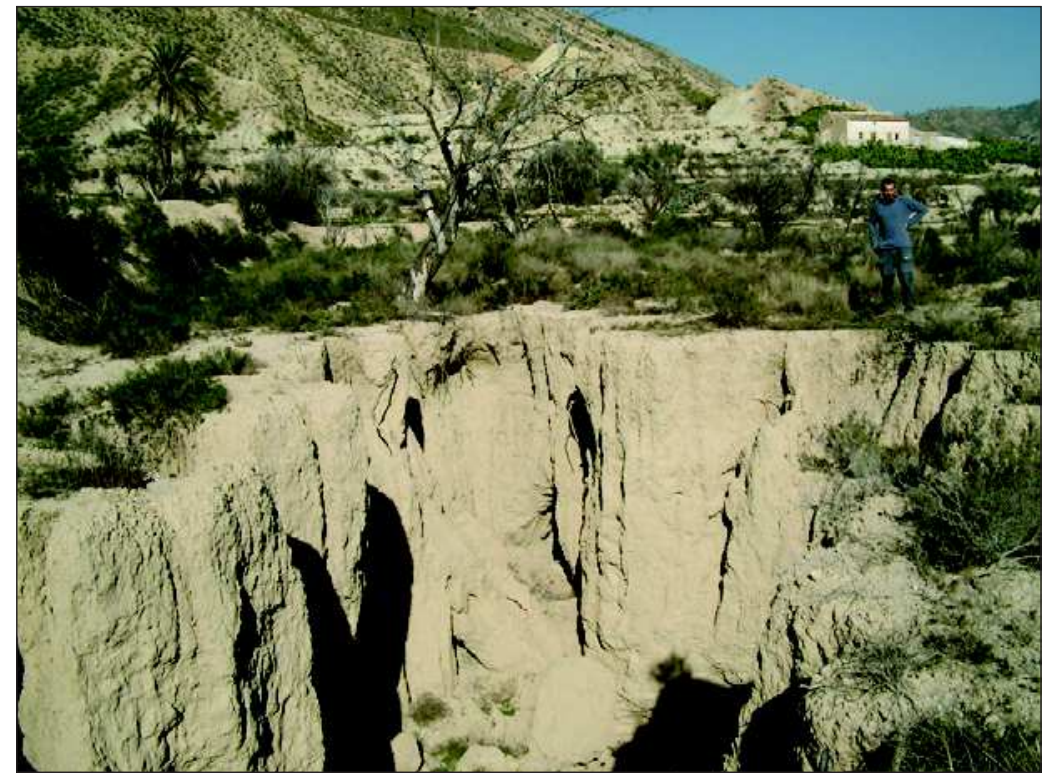

Fuente: A. Romero Díaz.

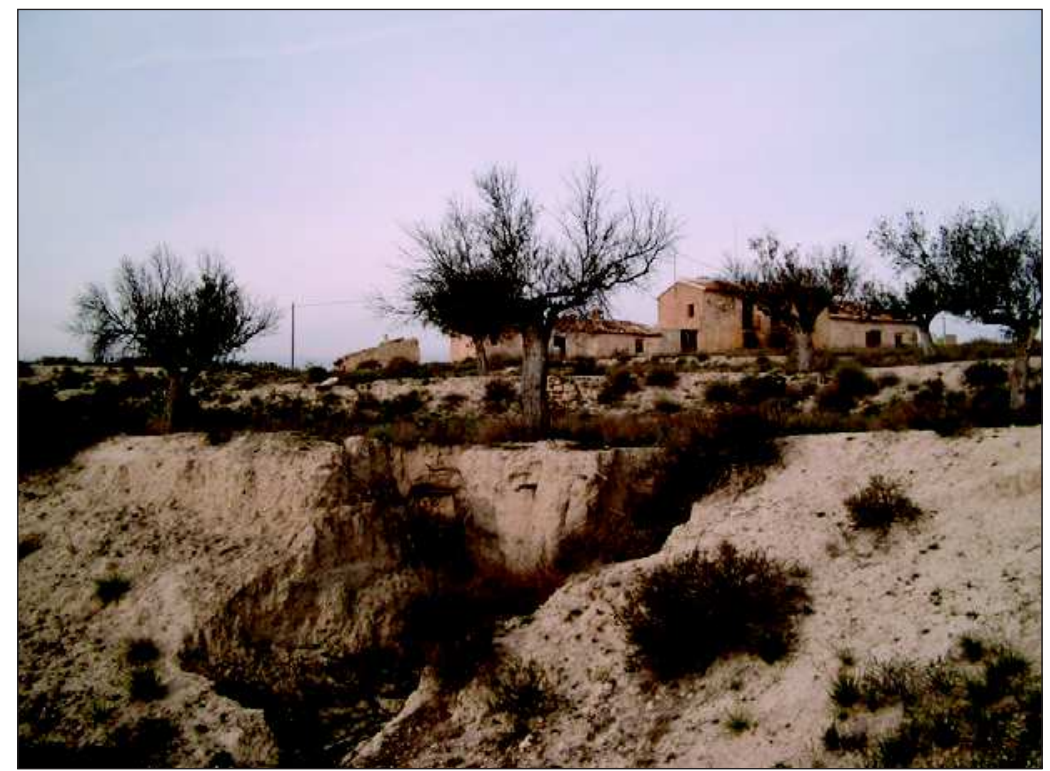

Fuente: A. Romero Díaz. 


\section{CONCLUSIONES}

Se constata, en la Comarca Oriental de la Región de Murcia, una superficie actual de abandono muy importante, al mismo tiempo que una evolución en progresivo aumento desde el año 1956. En las últimas décadas el abandono se ha extendido, favorecido en un primer momento, por la escasa capacidad de los suelos donde se asentó masivamente la actividad agrícola, ligada a un descenso general de la producción y la mejora en la intensificación de su práctica. Posteriormente, este fenómeno se ha podido ver favorecido por algunas de las políticas agrarias impuestas desde Europa, en particular con el subsidio de determinados cultivos. Las ayudas de la PAC para la retirada de tierras de cultivo, en esta comarca, apenas han tenido incidencia.

Tras el exhaustivo trabajo de fotointerpretación realizado de las áreas de abandono, mediante herramientas SIG, se observa que en 2011, cerca del $15 \%$ de la superficie comarcal se encontraba en abandono, con similar reparto a nivel municipal, tanto para Abanilla como para Fortuna. En cuanto a la edad o antigüedad que presentan estas áreas, cabe destacar que más de la mitad (el 56,8\%) lleva más de 10 años en estado de abandono. Estos valores son claves para futuras investigaciones acerca de las repercusiones del abandono en función del tiempo que transcurra desde el inicio de esta condición.

Los datos de las estadísticas agrarias analizados reflejan que la gran mayoría de estas zonas, antes de ser abandonadas, tenían un uso agrícola de secano, siendo los frutales no cítricos el cultivo mayoritario, encabezados por el almendro, además del viñedo y el olivar. El uso que se ha asignado al abandono, en la estadística agraria, en muchos casos, ha ido destinado a las superficies de terreno improductivo y terreno forestal, aunque también, en menor medida, a erial a pastos.

La amplia superficie en abandono de esta comarca, en su mayoría en áreas con desarrollo de importantes procesos de erosión, debería ser un factor determinante para alertar a las administraciones implicadas de que tienen que adoptar las medidas necesarias para mitigar los procesos de degradación, los cuáles originan altas tasas de pérdida de suelo y su posterior depósito en infraestructuras, llevando consigo un elevado coste. Es necesario tener voluntad para ponerlas en marcha, para que este territorio sea sostenible desde un punto de vista de producción y conservación.

\section{AGRADECIMIENTOS}

El trabajo se ha realizado en el marco del proyecto 15233/PI/10, financiado por la Fundación Séneca. A ella nuestro agradecimiento. Los autores agradecen a los revisores del manuscrito todas las observaciones realizadas, las cuales han contribuido, sin duda, a la mejora del mismo.

\section{REFERENCIAS}

ÁLVAREZ MARTÍNEZ, J. (1998): Dinámica sucesional tras el abandono y recuperación del matorral mediante pastoreo controlado. Experiencia en un sector de la montaña de León. Universidad de Lleida, $136 \mathrm{pp}$. 
ARNÁEZ, J., MARTÍ-BONO, C., BEGUERÍA, S., LORENTE, A., ERREA, M.P., GARCÍARUIZ, J.M. (2000): «Factores en la generación de avenidas en una cuenca de campos abandonados, Pirineo Central español». Cuadernos de Investigación Geográfica, $\mathrm{n}^{\circ}$ 25, 7-24.

ASINS VELIS, S. (2009): El paisaje agrario aterrazado. Dialogo entre el hombre y el medio en Petrer (Alicante). Serie Estudios y Documentos, 5. Publicacions de la Universitat de Valencia. 359 pp.

BALDOCK, D., BEAUFOY, G., BROUWER, F., GODESCHALK, F. (1996): Farming at the margins: Abandonment or redeployment of agricultural land in Europe. Institute for European Enviromental Policy, London/The Hague.

BAUDRY, J. (1991): «Ecological consequences of grazing extensification and land abandonment: role of interaction between environment, society and techniques». Options Méditerranéennes, $\mathrm{n}^{\circ} 15,13-19$.

BELMONTE SERRATO, F., ROMERO DÍAZ, A., LÓPEZ BERMÚDEZ, F. (1999): «Efectos sobre la cubierta vegetal, la escorrentía y la erosión del suelo, de la alternancia cultivo-abandono en parcelas experimentales». Investigaciones Geográficas, $\mathrm{n}^{\circ}$ 22, 95-107.

BELMONTE SERRATO, F., ROMERO DIAZ, A. (2007): «La cuenca de Abanilla - Fortuna» en Atlas Global de la Región de Murcia (Romero Díaz, A., Alonso Sarria, F., coord.) La Verdad CMM S.A. 500-511.

BONET, A. (2004): «Secondary succession of semi-arid Mediterranean old-fields in southeastern Spain: insights for conservation and restoration of degraded lands». Journal of Arid Environments, $\mathrm{n}^{\circ}$ 56, 213-233.

C. A. R. M. (2012, 2013): Estadística Agraria de la Región de Murcia. Consejería de Agricultura y Agua.

CAMMERAAT, L.H., IMESON, A.C. (1998): «Deriving indicator of soil degradation from soil aggregation studies in southeastern Spain and southern France». Geomorphology, $\mathrm{n}^{\circ}$ $23,307-321$

CERDÀ, A. (1994). «Arroyada superficial en terrazas de cultivo abandonadas. El caso del País valenciano». Cuadernos de Geografía, $\mathrm{n}^{\circ}$ 56, 136-154.

CERDÀ, A., GARCÍA ÁLVAREZ, A., CAMMERAAT, L.H., IMESON, A.C. (1994): «Agregación del suelo en una catena afectada por el abandono del cultivo en la cuenca del Guadalentín (Murcia). I. Estabilidad y distribución de los agregados del suelo» en Efectos Geomorfológicos del Abandono de Tierras (García Ruiz, J.M. y Lasanta, T., eds.). Sociedad Española de Geomorfología, Zaragoza, 9-19.

CERDÀ, A. (1995): «Impacto del abandono del cultivo sobre la pérdida de suelo y agua en un ambiente semiárido. Cuenca del río Guadalentín, Murcia». XIV Congreso Nacional de Geografía, Salamanca, 74-79.

CERDÀ, A., GARCÍA ÁLVAREZ, A., CAMMERAAT, L.H., IMESON, A.C. (1995a): «Fluctuación estacional y dinámica microbiana en una catena afectada por el abandono del cultivo en la cuenca del Guadalentín (Murcia)», Pirineos, n $145-146,3-11$.

CERDÀ, A., BOIX, C., SORIANO, M.D., CALVO, A., IMESON, A. (1995b): «Degradación del suelo en una catena sobre margas afectada por el abandono del cultivo en un ambiente semiárido». Cuaternario y Geomorfología, n ${ }^{\circ} 9$ (3-4), 59-75.

CERDÀ, A. (1997): «Soil erosion after land abandoment in a semiarid environment of Southeasterm Spain». Arid Soil Research and Rehabilitation, $\mathrm{n}^{\circ}$ 11, 163-176. 
CORBELLE RICO, E., CRECENTE MASEDA, R. (2008): «El abandono de tierras: concepto teórico y consecuencias». Revista Galega de Economía, n ${ }^{\circ} 17$ (2), 1-15.

FERRE BUENO, E., ASENSI MARFIL, A., SENCIALEZ GONZÁLEZ, J.M. (1994): «Procesos de erosión y dinámica de la vegetación en bancales abandonados en el Valle de Andarax (prov. de Almería)» en Efectos Geomorfológicos del Abandono de Tierras (García Ruiz, J.M. y Lasanta, T., eds.) Sociedad Española de Geomorfología, Zaragoza, 31-41.

FRANCIS, C. (1986): «Variaciones sucesionales y estacionales de vegetación en campos abandonados de la provincia de Murcia». Ecología, n 4, 35-47.

GALLART, F., LLORENS, P. (1994). «El papel de los cultivos de montaña y su abandono en la economía del agua» en Efectos Geomorfológicos del Abandono de Tierras (García Ruiz, J.M. y Lasanta, T., eds.) Sociedad Española de Geomorfología, Zaragoza, 43-55.

GARCÍA-RUIZ, J.M. (2010): «The effects of land uses on soil erosion in Spain: a review». Catena, $\mathrm{n}^{\circ} 81,1-11$.

GARCÍA, C. ROLDAN, A., HERNÁNDEZ, T. (1997): «Changes in microbial activity after abandonment of cultivation in a semiarid Mediterranean environment». Journal of Environmental Quality, n 26, 285-291.

GARCÍA RUIZ, J.M., LASANTA, T., SOBRÓN, I. (1988): «Problemas de evolución geomorfológica en campos abandonados: El valle del Jubera (Sistema Ibérico)». Zubía, no 6, 99-114.

GARCÍA RUÍZ, J.M., RUIZ FLAÑO, P., LASANTA,T., MONTSERRAT,G., MARTÍNEZ RICA, J.P., PARDINI,G. (1991): «Erosion in abandoned fields, what is the problem?» en Soil erosion studies in Spain (Sala, M., Rubio, J.L. y García-Ruíz, J.M., eds.). Geoforma Ediciones, Logroño, 97-108.

GARCÍA RUIZ, J.M., LASANTA, T. (Eds.) (1994): Efectos Geomorfológicos del Abandono de Tierras. Sociedad Española de Geomorfología, 171, Zaragoza.

GARCÍA RUIZ, J.M., RUIZ FLAÑO, P., LASANTA, T. (1996): «Soil erosion after farmland abandonment in submediterranean mountains: A general outlook» en Soil degradation and desertification in Mediterranean environments (Rubio, J.L. y Calvo, C., eds.). Geoforma Ediciones, Logroño. 165-183.

GARCÍA-RUIZ, J.M., LANA-RENAULT, N. (2011): «Hydrological and erosive consequences of farmland abandonment in Europe, with special reference to the Mediterranean region. Agriculture». Ecosystems and Environment, n 140, 317-338.

KOSMAS, C., YASSOGLOU, N., KOUNALAKI, JAIRIS, O. (2008): Abandono de cultivos. Lucinda (Land Care in Desertification Affected Areas). From Science Towards Application, 4.

LANA-RENAULT, N., LATRON, J., REGÜÉS, D., SERRANO, P. y NADAL, E. (2008): «Diferencias estacionales en la generación de escorrentía en una pequeña cuenca de campos abandonados en el Pirineo Central». Cuadernos de Investigación Geográfica, $\mathrm{n}^{\circ}$ 34, 22-37.

LASANTA, T., RUIZ FLAÑO, P., ORTIGOSA, L., GARCÍA RUÍZ, J.M. (1994a): «Cultivo frente a abandono de tierras en laderas de montaña. Primeros resultados hidrogeomorfológicos» en Efectos Geomorfológicos del Abandono de Tierras (García Ruiz, J.M. y Lasanta, T., eds.). Sociedad Española de Geomorfología, Zaragoza, 83-93. 
LASANTA, T, ORTIGOSA, L., GARCÍA RUIZ, J.M. (1994b): «Distribución espacial de diferentes modelos de campos de cultivo en el Pirineo central español». Eria, 63-72.

LASANTA, T., VICENTE-SERRANO, S.M., CUADRAT, J.M. (2000): «Marginación productiva y recuperación de la cubierta vegetal en el Pirineo: un caso de estudio en el valle de Borau». Boletín de la Asociación de Geógrafos Españoles, n 29, 5-28.

LASANTA, T., VICENTE SERRANO, S.M. (2007): «Cambios en la cubierta vegetal en el Pirineo aragonés en los últimos 50 años». Pirineos, ${ }^{\circ}{ }^{162}$, 125-154.

LLORENS, P., QUERALT, I., PLANA, F. (1992): «Balance de sedimentos y caracterización de los materiales de las áreas fuente y los sedimentos transportados en una pequeña cuenca de campos abandonados (Cal Parisa)» en Estudios de Geomorfología en España (López Bermúdez, F., Conesa García, C. y Romero Díaz, A., eds.), SEG, Murcia, Vol 1, 83-92.

LLORENS, P., GALLART, F. (1994): «Consecuencias hidrológicas de la reforestación de los campos abandonados: diseño y resultados preliminares de un experimento en Cal Parisa (Vallcebre)» en Efectos Geomorfológicos del Abandono de Tierras (García Ruiz, J.M. y Lasanta, T., eds.) Sociedad Española de Geomorfología, Zaragoza, 95-106.

LÓPEZ BERMÚDEZ, F., ROMERO DÍAZ, A. (1998): «Erosión y desertificación: implicaciones ambientales y estrategias de investigación». Papeles de Geografía, ${ }^{\circ}{ }^{28}$, 77-89.

MARCO-MOLINA, J.A., MORALES GIL, A. (1995): «Terrazas de cultivo abandonadas en el sureste peninsular: aspectos evolutivos». Investigaciones Geográficas, $\mathrm{n}^{\circ}$ 13, 81-90.

MARTINEZ FERNÁNDEZ, J., MARTÍNEZ FERNÁNDEZ, J., LÓPEZ BERMÚDEZ, F., ROMERO DÍAZ, A., BELMONTE SERRATO (1996): «Evolution of vegetation and pedological characteristictics in fields with different age of abandonment: A case study in Murcia (Spain)» en Soil Degradation and Desertification in Mediterranean Environments (Rubio, J.L. y Calvo, A., eds.). Geoforma Ediciones. Logroño, 279-290.

MOLINA-GALLART, D., NADAL-TERSA, J. (1998): «Procesos erosivos en campos abandonados del Parque Natural del Cadí-Moixeró (Pirineos Orientales)» en Investigaciones recientes de la Geomorfología española (Gómez Ortiz, A. y Salvador Franch, F., eds.), SEG-UGR, Barcelona, 539-546.

ORTIZ SILLA, R. (2007): «Los suelos» en Atlas Global de la Región de Murcia (Romero Díaz, A., Alonso Sarria, F., coord.). La Verdad CMM S.A. 176-187.

PADILLA BLANCO, A. (1998). Colonización vegetal en campos abandonados de la provincia de Alicante. Universidad de Alicante, 365 pp.

PÉREZ LATORRE A.V., CABALLERO, G., CASIMIRO SORIGUER, F., GAVIRA, O., CABEZUDO, B. (2008): «Vegetación del sector Malacitano-Axarquiense (comarca de la Axarquía, Montes de Málaga y Corredor de Colmenar). Málaga (España)». Acta Bot. Malacitana $\mathrm{n}^{\circ} 33,215-270$.

POINTERAU, P., COULON, F., GIRARD, P., LAMBOTTE, M., STUCZYNSKI, T., SÁNCHEZ, V., DEL RIO, A. (2008): Analysis of farmland abandonment and the extent and location of agricultural areas that are actually abandoned or are in risk to be abandoned. Institute for environment and sustainability, Join Reserch Centre, EC.

ROBLEDANO, F., ZAPATA, V., ROMERO DIAZ, A., BELMONTE, F. (2012): «Evaluación preliminar de patrones de riqueza de plantas leñosas en campos abandonados sobre diferentes litologías en la Región de Murcia». Las zonas de montaña: gestión y biodiversidad. GRAMP. Fundació CatalunyaCaixa y Universidad Autónoma de Barcelona, 46-52. 
ROBLEDANO, F., ROMERO-DÍAZ, A., BELMONTE-SERRATO, F., ZAPATA-PÉREZ, V.M., MARTÍNEZ-HERNÁNDEZ, C., MARTÍNEZ LÓPEZ, V. (2014): «Ecogeomorphological consequences of land abandonment in semiarid mediterranean areas: integrated assessment of physical evolution and biodiversity». Agriculture, Ecosystems \& Environment, $\mathrm{n}^{\circ}$ 197, 222-242.

RODRÍGUEZ AIZPEOLEA, PÉREZ-BADIA, R., CERDA BOLINCHES, A. (1991): «Colonización vegetal y producción de escorrentía en bancales abandonados: Valle de Gallinera, Alacant». Cuaternario y Geomorfología, n ${ }^{\circ}$ 5, 119-129.

ROMERO DÍAZ, A. (2003): «Influencia de la litología en las consecuencias del abandono de tierras de cultivo en medios mediterráneos semiáridos». Papeles de Geografía, n 38, 151-165.

ROMERO DÍAZ, A., MARÍN SANLEANDRO, P., SÁNCHEZ SORIANO, A., BELMONTE SERRATO, F., FAULKNER, H. (2007): «The causes of piping in a set of abandoned agricultural terraces in Southeast Spain». Catena, $\mathrm{n}^{\circ}$ 69, 282-293.

ROMERO DIAZ, A., ROBLEDANO, F., BELMONTE, F., ZAPARA, V., RUIZ SINOGA, J.D. (2012): «Influencia del abandono de cultivos en los procesos de degradación de suelos en la Región de Murcia». Avances de la Geomorfología en España (2010-2012). Ediciones Universidad de Cantabria, 578-591.

ROMERO DÍAZ, A., MARTÍNEZ HERNÁNDEZ, C. (2014): «Usos del suelo y abandono de tierras de cultivo en el Altiplano Jumilla-Yecla (Región de Murcia)». Geoecología, cambio global y paisaje. Instituto Pirenaico de Ecología (CSIC) y Universidad de La Rioja, 461-470.

RUECKER, G., SCHAD, P., ALCUBILLA, M.J., FERRER, C. (1998): «Natural regeneration of degraded soils and site changes on abandoned agricultural terraces in Mediterranean Spain». Land Degradation \& Development, $\mathrm{n}^{\circ} 9$ (2), 179-188.

RUIZ-FLAÑO, P., ORTIGOSA, L., GARCÍA-RUIZ, J.M. (1991): «Distribución espacio-temporal de los microambientes geomorfológicos en campos abandonados en pendiente (Valle de Aísa, Pirineo aragonés)». Cuadernos de Investigación Geográfica, nº 17, 89-101.

RUIZ-FLAÑO, P. (1993): Procesos de erosión en campos abandonados del Pirineo. El ejemplo del valle de Aisa. Geoforma Ediciones, Logroño, $191 \mathrm{pp}$.

RUÍZ SINOGA, J.D., MARTÍNEZ MURILLO, J.F. (2003): «Respuesta erosiva de laderas con diferentes usos antrópicos en la vertiente meridional de los Montes de Málaga» en Control de la erosión y degradación del suelo (Bienes, R. y Marqués, M.J., eds.). Instituto Madrileño de Investigaciones Agrarias, 471-474.

RUÍZ SINOGA, J.D., MARTÍNEZ MURILLO, J.F. (2008): «Soil degradation analysis by means of the soil water content and vegetal cover monitoring at abandoned field hillslopes in the south of Spain». Drylands, Deserts and Desertification. Sede Boquer (Israel).

RUÍZ SINOGA, J.D., MARTÍNEZ MURILLO, J.F. (2009): «Changes of Soil-Water-Plants relationships at abandoned field hillslopes along a pluviometric gradient in the South of Spain». Geophysical Research Abstracts, Vol. 11, EGU2009-1572-1, 2009. EGU General Assembly, Viena.

RUÍZ SINOGA, J.D., ROMERO DÍAZ, A. (2009): «Effects in the ecogeomorphological system of the inter-annual rainfall variability at long term abandoned hillslope.(South of Spain)». Geophysical Research Abstracts, vol. 11,EGU2009-13109, 2009. EGU General Assembly, Viena. 
RUÍZ SINOGA, J.D., MARTÍNEZ MURILLO, J.F., DELGADO PEÑA, J.J., GALLEGOS REINA, A., LUCAS SANTAMARÍA, B., MÁRQUEZ CARRERO, J., NOGUERA ROBLES, M.J., ROMERO LOPERA, A.R. (2003): «Variabilidad de los procesos de generación de escorrentía en laderas bajo condiciones mediterráneas». Baetica, $\mathrm{n}^{\circ} 25$, 279-312.

VICENTE-SERRANO, S.M., BEGUERIA, S., LASANTA, T. (2006): «Diversidad espacial de la actividad vegetal en campos abandonados del Pirineo central español. Análisis de los procesos de sucesión mediante imágenes Landsat (1984-2001)». Pirineos $\mathrm{n}^{\circ} 161$, 59-84. 